Research Paper

\title{
Virulence profiles of Shiga Toxin-Producing Escherichia coli and other potentially diarrheagenic E.coli of bovine origin, in Mendoza, Argentina.
}

\author{
M.A. Pizarro ${ }^{1}$, J.H. Orozco ${ }^{1}$, S.M. Degarbo ${ }^{1}$, A.E. Calderón ${ }^{1}$, A.L. Nardello ${ }^{1}$, \\ A. Laciar $^{2}$, M.E. Rüttler ${ }^{1}$ \\ ${ }^{1}$ Departamento de Morfofisiología, Laboratorio de Biología Molecular, Facultad de Ciencias Médicas, \\ Universidad Nacional de Cuyo, Mendoza, Argentina. \\ ${ }^{2}$ Cátedra de Microbiología, Facultad de Bioquímica, Química y Farmacia, \\ Universidad Nacional de San Luis, San Luis, Argentina.
}

Submitted: July 27, 2011; Approved: April 04, 2013.

\begin{abstract}
This study described a group of strains obtained from a slaughter house in Mendoza, in terms of their pathogenic factors, serotype, antibiotype and molecular profile. Ninety one rectal swabs and one hundred eight plating samples taken from carcasses of healthy cattle intended for meat consumption were analyzed. Both the swab and the plate samples were processed to analyze the samples for the presence of virulence genes by PCR: stxl, stx2, eae and astA. The Stx positive strains were confirmed by citotoxicity assay in Vero cells. The isolates were subsequently investigated for their O:H serotype, antimicrobial susceptibility and molecular profile by Random Amplification of Polymorphic DNA (RAPD). Twelve E.coli strains were identified by their pathogenicity. Nine were from fecal origin and three from carcasses. Three strains carried the stx 1 gene, three the stx 2 gene, two carried eae and four the astA gene. The detected serotypes were: O172:H-; O150:H8; O91:H21; O178:H19 and $\mathrm{O} 2$ :H5. The strains showed a similarity around $70 \%$ by RAPD. Some of the E.coli strains belonged to serogroups known for certain life-threatening diseases in humans. Their presence in carcasses indicates the high probability of bacterial spread during slaughter and processing.
\end{abstract}

Key words: Hemolitic Uremic Syndrome (HUS), Shiga Toxin Escherichia coli (STEC), Enteroaggregative Stable toxin (EAST1), Enteropathogenic Escherichia coli (EPEC), foodborne diseases, cattle.

\section{Introduction}

As a result of changes in our daily lives, routines, and eating habits, diseases caused by the consumption of contaminated food have become a major morbimortality cause around the world (Prado et al., 2002).

Nearly 250 agents causing foodborne diseases have been described, including bacteria, viruses, fungi, parasites, prions, toxins, and metals. The incidence of these diseases is a direct indicator of the hygienic-sanitary quality of food. Food contamination may occur during food processing or may be due to the use of contaminated raw material, since some bacteria that form part of the natural flora of poultry, pigs, and cattle are pathogenic for humans as well.
Foodborne diseases pose a major Public Health problem because of the increasing number of episodes, the emergence of new forms of transmission, the appearance of vulnerable population groups, the increasing pathogen resistance to antimicrobial compounds, and their socioeconomic impact (Prado et al., 2002; Ruttler et al., 2002).

The detection and investigation of foodborne outbreaks constitute one of the main challenges to the Public Health System since they require access to medical information (personal data, symptoms, etc.) and laboratory analysis of leftover food or of the raw material used during the production process, and even of the hands of those involved in food handling, in a timely and efficient manner(Blanco et al., 2004; Rivas, 2009; Rivas et al., 2006; Rivero et al., 2004).

Send correspondence to M.E. Rüttler. Departamento de Morfofisiología, Laboratorio de Biología Molecular, Facultad de Ciencias Médicas, Universidad Nacional de Cuyo, Av. Libertador 80, 5500 Mendoza, Argentina. E-mail: mruttler@fcm.uncu.edu.ar. 
Escherichia coli is a genetically heterogeneous group of bacteria whose members are typically nonpathogens that are part of the normal microflora of the intestinal tract of humans and animals. However, certain subsets of this bacterium have acquired genes that enable them to cause intestinal and extraintestinal disease. Those strains that cause enteric infections are generally called diarrheigenic $E$. coli strains, and their pathogenesis is associated with a number of virulence attributes, which vary according to pathotype. Currently, diarrheagenic $E$. coli strains are classified into six main pathotypes based on their distinct virulence determinants and pathogenic features, including enteropathogenic E. coli (EPEC), enterotoxigenic E. coli (ETEC), enterohemorragic E. coli (EHEC)/Shiga toxin-producing $E$. coli (STEC), enteroinvasive E. coli (EIEC), enteroaggregative E.coli (EAEC), and diffusively adherent E. coli (DAEC)(Ruttler et al., 2006; Xia et al., 2010).

Among diarrheagenic E. coli, STEC is distinguished by the ability to cause severe illnesses in humans such as hemorrhagic colitis (HC), hemolytic uremic syndrome (HUS), and thrombotic thrombocytopenic purpura. Due to the severity of these diseases, particularly when they affect children, and the low infectious doses that characterize not only the outbreaks but also the sporadic cases (less than $100 \mathrm{cfu} / \mathrm{g})($ Ollero et al., 2004), this pathogen has been ranked as one of the foodborne pathogens that poses the greatest risk to public health. According to the Pan American Health Organization, the HUS is endemic in Argentina. Around four hundred new cases are reported annually by nephrological units from hospitals (Rivas, 2009). The incidence has been estimated to correspond to 15 cases per 100,000 children under 5 years of age, and more than 7,000 cases have been registered since 1965 (Mercado, 2007; Rivas, 2009).

Cattle are the main reservoir of STEC, and poorlycooked minced meat the most frequently reported vehicle of transmission. The largest number of cases is reported during the hottest months of the year as the number carrying the pathogen and the vehicles of transmission increase during that period (Gomez et al., 2002; Marzocca et al., 2006; Rivas et al., 2006; Rivero et al., 2004).

Human and bovine STEC produce two potent phageencoded cytotoxins, called Shiga-toxins (Stx1 and Stx2). In addition to toxin production, another virulence-associated factor expressed by STEC is a protein called intimin, which is responsible for intimate attachment of STEC to the intestinal epithelial cells, causing attaching and effacing (A/E) lesions in the intestine. A small heat-stable enterotoxin known as EAST1 (Enteroaggregative Stable Toxin 1), codified in the chromosome of STEC by the ast $A$ gene, (Doyle and Schoeni, 1984; Hornitzky et al., 2005; McNally et al., 2005; Ollero et al., 2004; Veilleux and Dubreuil, 2006).

A large variety of serotypes have been isolated from humans with gastrointestinal disease and many of these serotypes as well as others have been recovered from ani- mals. The serotypes associated with illness in humans vary in frecuency with the country and year, the list includes members of O serogroups 26, 91, 103, 111, 113, 121, 145 and 157 (Karmali et al., 2010).

The first study of risk factors for sporadic STEC infections in Argentina (conducted in Buenos Aires and Mendoza) demonstrated a broad range of factors associated with transmission. Undercooked beef in many forms was the most risky food (Rivas et al., 2006). Up to now, STEC presence in cattle raised for beef consumption in the province of Mendoza has not been assessed. In this study, we examined the presence of STEC strains in 91 rectal swabs and 108 carcass samples of bovines in a slaughter house in Mendoza, Argentina. In addition, we examined the presence of other potentially diarrheagenic E.coli (EPEC and EAEC). Furthermore, we characterized the isolates with virulence genes in terms of pathogenicity, serotype, antibiotype, and molecular profile to assess bacterial contamination of retails meats and to establish a database of STEC strains circulating in our environment so that it may be used as a source of comparison in the eventuality that sporadic cases or outbreaks may occur in susceptible populations.

\section{Material and Methods}

\section{Samples}

Ninety one rectal swabs of 91 animals intended for slaughter and 108 plating samples from the carcasses of 50 of them were analyzed during a period of nine months in 2006. The samples were taken according to the rules and regulations set forth by SENASA, the organization that controls agriculture and livestock farming in Argentina. Once the animals were killed, they were carried to the place of slaughter where a sample of the intestinal content was taken using a sterile swab. This procedure was carried out during the anal enucleation of animals. The swabs were introduced in Cary Blair transport medium and processed within 6 hours after the procedure. Samples were seeded in trypticase soy agar (TSA) plates; Colony count was performed after $24 \mathrm{~h}$ incubation at $37^{\circ} \mathrm{C}$.

Petri plates with Casoy agar were used to sample the carcasses, 1 to 4 plate/animal, a total of 108 samples.

The plates were incubated $18 \mathrm{~h}$ at $37^{\circ} \mathrm{C}$. From then on, both the plates from swab and carcasses were processed in the same way:

\section{PCR detection of genes encoding pathogenic factors}

The bacteria grown in each Petri plate were resuspended in Casoy broth and incubated for $18 \mathrm{~h}$ at $37^{\circ} \mathrm{C}$ under agitation. One milliliter of this bacterial suspension was suspended in $150 \mu \mathrm{L}$ of Triton $1 \%$ on buffer TE, on an eppendorf tube. The tube was boiled for $10 \mathrm{~min}$ and centrifuged at 10,000 rpm. The supernatant was used as a template for the PCR reaction (Miliwesbsky, 2006). 
An aliquot of the bacterial suspension was kept at $-70{ }^{\circ} \mathrm{C}$ and another one underwent biochemical tests.

A total of 199 (91 rectal swabs and 108 carcass) samples were subjected to PCR; stx1, stx2, eae, aggR and ast A genes were detected using the primers described in Table 1. Stx1, Stx2, belong to STEC/EHEC, eae to EPEC, aggR to EAEC and astA to EAEC and EHEC. Control reference strains were $E$. coli EDL 933 (O157:H7, stx1, stx2, eae, astA), E.coli AA17/2 (O3:H2, aggR and ast A) and E. coli $\mathrm{K} 12$ (negative control).

All reactions were carried out in $50 \mu \mathrm{L}$ reaction volumes containing $2 \mu \mathrm{L}$ of bacterial lysate, $200 \mathrm{mmol}$ of deoxynucleotide mix (dATP, dTTP, dCTP, and dGTP), 100 pmol of each primer, $5 \mu \mathrm{L}$ of 10XPCR buffer with $1.5 \mathrm{mM} \mathrm{MgCl}_{2}$, and $2.5 \mathrm{U}$ of Taq DNA polymerase (InbioHighway). The reactions were performed in an Eppendorf Mastercycler personal termocycler. The PCR products were electrophoresed in $2 \%$ agarose gel in $1 \mathrm{X}$ TBE (0.1 M Tris, $0.09 \mathrm{M}$ boric acid and $1 \mathrm{mM}$ EDTA) and the gels were stained with ethidium bromide and photographed using UV light.

After the screening by PCR, the positive broths were reseeded on plates, and then pools of 10 colonies were tested again until the colony carrying the gene was found. Twelve E.coli strains with virulence factors were isolated.

\section{Biochemical tests}

After the screening by PCR the strains with virulence factors were identified by standard biochemical tests as oxidase negative, indole positive, Simon's citrate negative, urease negative, and hydrogen sulfide negative. (MacFaddin, 2003).

\section{Serotypification}

Isolates containing a virulence factor were serotyped in the Immunochemistry and Biotechnology Unit of the Animal Health Department at the School of Veterinary Science of the National University of the Center of the Buenos Aires Province. The following antisera have been tested so far in the isolated samples for somatic antigens: $\mathrm{O} 1, \mathrm{O} 2$, O4, O5, O6, O8, O9, O15, O16, O17, O20, O22, O25, O26, O27, O32, O39, O41, O45, O46, O48, O55, O64, O74, O75, O77, O81, O82, O84, O86, O88, O91, O98, O101, O103, O104, O105, O109, O110, O111, O112, O113, O116, O117, O118, O119, O121, O123, O126, O128, O132, O136, O139, O141, O145, O146, O150, O153, O157, O162, O163, O165, O166, O168, O171, O172, $\mathrm{OX} 3=\mathrm{O} 174, \mathrm{O} 176, \mathrm{O} 177$ and $\mathrm{O} 178$.

For flagellar antigens $\mathrm{H}_{1}$ to $\mathrm{H}_{56}$ antisera were used.

\section{Subtypification}

The RAPD (Random Amplified Polymorphic DNA) technique was used for this purpose. This technique, based in a PCR reaction, was developed according the protocol of the Immunochemistry and Biotechnology Unit of the Animal Health Department at the School of Veterinary Science of the National University of the Center of the Buenos Aires (Padola et al., 2004; Pichel, 2006).

The Primers used were M13 5'GAGGGTGGCG GTTCT3' and 970-11 5'GTAAGGCCG3'.

\section{Analysis of DNA patterns}

Ethidium Bromide stained gels were registered with a Cannon Powershot camera and images were stored as tagged image format files. DNA patterns obtained with the RAPD technique were analyzed with NTSYSpc Numerical Taxonomy System 2001 Exeter software. Similarities between the DNA patterns of eleven of the twelve E. coli isolates based on band positions were determined by using the Dice similarity coefficient, and a dendrogram was constructed by using the unweighted pair group method with arithmetic averages to reflect similarities in the matrix. $E$. coli isolates were grouped into genetic subtypes which were considered genetically related ( $80 \%$ similarity) based on DNA patterns.

Table 1 - Oligonucleotide primers used in this study.

\begin{tabular}{|c|c|c|c|}
\hline Primer & Primer sequence $\left(5^{\prime}-3^{\prime}\right)$ & Product size bp & Reference source \\
\hline Stx 1 forward & GAAGAGTCCGTGGGATTACG & 130 & (Pollard et al., 1990) \\
\hline Stx1 reserve & AGCGATGCAGCTATTAATAA & & \\
\hline Stx2forward & TTAACCACACCCCACCGGGCAGT & 346 & (Pollard et al., 1990) \\
\hline Stx2reverse & GCTCTGGATGCATCTCTGGT & & \\
\hline eae forward & TGA GCG GCT GGC ATG AGT CAT AC & 240 & (Pass et al., 2000) \\
\hline eae reverse & TCG ATC CCC ATC GTC ACC AGA GG & & \\
\hline ast $\mathrm{A}$ forward & GCC ATC ACA GTA TAT CCG & 108 & (Ruttler et al., 2002) \\
\hline ast $\mathrm{A}$ reverse & GCG AGT GAC GGC TTT GTA GT & & \\
\hline AggR forward & AGA CGC CTA AAG GAT GCC C & 430 & (Ruttler et al., 2002) \\
\hline AggR reverse & GAG TTA TCA AGC AAC AGC AAT GC & & \\
\hline
\end{tabular}




\section{Antimicrobial susceptibility testing}

Antimicrobial susceptibilities of the isolates were performed on Mueller Hinton agar by disk diffusion method according to Clinical and Laboratory Standards Institute (CLSI). The antimicrobial agents tested were amicacine, ampicillin, ciprofloxacin, colistin, cloramphenicol, gentamicin, nalidixid acid, nitrofurantoin, streptomycin, tetracycline and trimethoprim-sulphamethoxazole. Escherichia coli ATCC 25922 was used as control strain (Miliwesbsky, 2006).

\section{Cytotoxicity assay on Vero Cells}

A group of 6 strains characterized as STEC by PCR were tested. The 933J strain, carrying Stx1 toxins, and the 933W strain, carrying Stx2 toxins, were used as positive control, and the HS strain, which does not have cytotoxins, was used as negative control. The technique consisting in seeding microplates with Vero cells passage $8.5 \times 10^{4}$ cells per well were inoculated into a 96 plate, and were cultured with Minimum Essential Medium (MEM) supplemented with 10\% Bovine Calf Serum (BCS).

The wells were inoculated in duplicate with $50 \mu \mathrm{L}$ of the samples for the screening test. Samples with positive PCR results were inoculated in serial dilutions for the titration. They were incubated at $37{ }^{\circ} \mathrm{C}$ and read daily. The cytotoxic activity was determined 72 hours later, and was evidenced by alterations in the monolayer of cells. A 50\% cytotoxic dose (CD50) was considered as the inverse function of the highest dilution presenting activity in $50 \%$ of the monolayer (Miliwesbsky, 2006).

The viability of the Vero cells was determined by crystal violet staining.

\section{Results \\ Presence of pathogenic factors in rectal swabs and carcasses}

Among the 91 fecal samples under study, the PCR screening showed that $11 \%$ possessed Stx 1 genes, $12 \%$ Stx 2, 4\% were EAST1 positive, $6 \%$ possessed eae (eae was associated with the Stx2 toxin in two samples) and none was $\operatorname{aggR}$ positive (Figure 1).

Among the 108 carcass samples, 4.32\% were Stx2, $2.77 \%$ Stx $1 / \mathrm{Stx} 2,0.93 . \%$ ast $\mathrm{A} 1.85 \%$ eae and none was $\operatorname{aggR}$ positive (Figure 2).

After the screening, as a result of the characterization performed, a total of 12 E.coli strains carrying pathogenicity factors were confirmed. The isolated strains belonged to serotypes O172:H(-), O150:H8, O178:H19, O2:H5, O91:H21. Some strains could not be grouped with $\mathrm{O}$-antigen, but could be grouped with the $\mathrm{H}$-antigen, resulting in H42, H46, H16, and H21. Table 2 shows the strains characteristics.

Among the 12 E.coli isolates, 3 contained the st 1 gene, and 3 the stx 2 gene. None of the STEC isolates in this

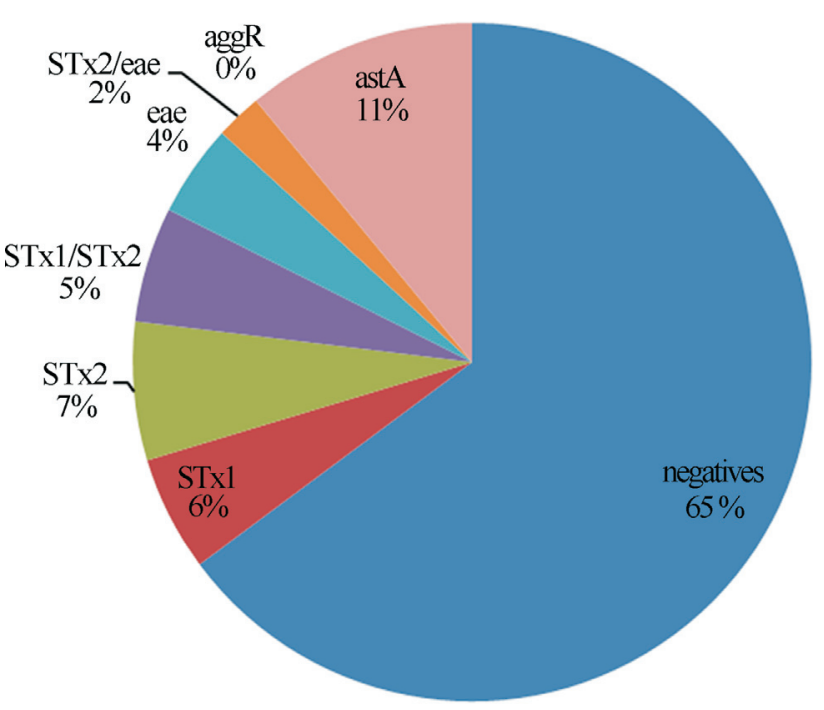

Figure 1 - Screening by PCR in rectal swabs. Percentages of pathogenics factors in 91 samples.

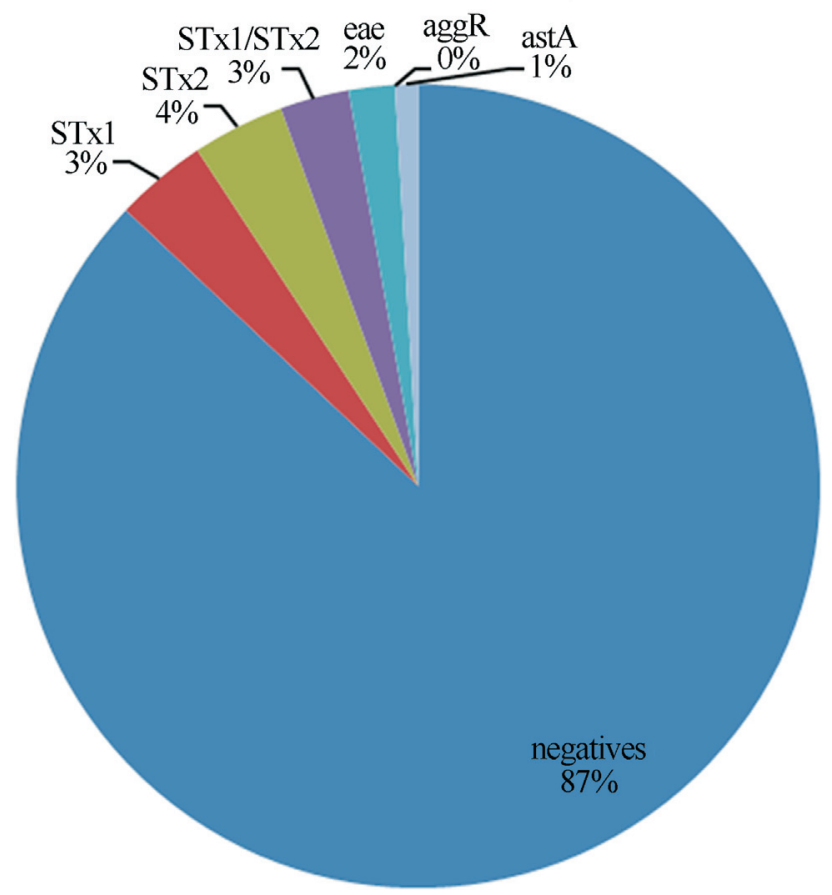

Figure 2 - Screening by PCR in carcasses. Percentages of pathogenics factors in 108 samples.

study carried the eae gene, while four strains were ast $\mathrm{A}$ positive only.

\section{Sensitivity to antimicrobial agents}

Antimicrobial sensitivity was assessed in the $12 \mathrm{E}$. coli isolates; $100 \%$ of the strains showed susceptibility to ciprofloxacin and sulphamethoxazol-trimethoprim while most of them were resistant to colistin. One strain eae positive ONT:H46 showed resistance to four antibiotics and intermediate sensitivity to three of them. Another strain ast A 
Table 2 - Pathogenic factors, serotype and origin of the twelve E.coli strains isolated.

\begin{tabular}{|c|c|c|c|c|c|c|}
\hline \multirow[t]{2}{*}{ Strain number } & \multicolumn{4}{|c|}{ Pathogenic factor by PCR } & \multirow[t]{2}{*}{ Serotype } & \multirow[t]{2}{*}{ Origin } \\
\hline & Stx1 & Stx2 & eae & astA & & \\
\hline 1 & + & - & - & - & ONT:H42 & intestine \\
\hline 2 & - & - & + & - & ONT:H(-) & carcasse \\
\hline 3 & - & - & + & - & ONT:H46 & carcasse \\
\hline 4 & - & + & - & - & $\mathrm{O} 172: \mathrm{H}(-)$ & carcasse \\
\hline 5 & - & - & - & + & O150:H8 & intestine \\
\hline 6 & - & - & - & + & ONT:H? & intestine \\
\hline 7 & - & - & - & + & ONT:H? & intestine \\
\hline 8 & - & - & - & + & ONT:H16 & intestine \\
\hline 9 & - & + & - & - & O91:H21 & intestine \\
\hline 10 & + & - & - & - & ONT:H? & intestine \\
\hline 11 & - & + & - & - & O178:H19 & intestine \\
\hline 12 & + & - & - & - & $\mathrm{O} 2: \mathrm{H} 5$ & intestine \\
\hline
\end{tabular}

positive ONT:H?, was resistant to six out of the twelve antibiotics tested. This strain cannot be classified as STEC as it lacks the Stx genes and it does not react to any of the serogroups used. However, it does present a virulence factor, the astA gene, that does cause disease in humans; hence, its pathogenic potential should not be disregarded. Table 3 shows the results.

\section{Cytotoxicity assay}

The Escherichia coli strains that were positive for some of the Stx 1 or Stx 2 toxins by PCR were analyzed by means of the cytotoxicity assay, as it is described in the methodology (Figure 3).

All the strains could be confirmed due to their cytotoxic effect.

Cytotoxic dose $50 \%\left(\mathrm{CD}_{50}\right)$ was calculated as the reciprocal of the toxin dilution causing $50 \%$ reduction in cellular viability. Three of the seven strains tested showed citotoxic effect. As this technique is used as the reference test, positive samples were confirmed as toxigenic. The O91:H21 strain presented a $\mathrm{CD}_{50}=1600$, O 178:19 strain $\mathrm{CD}_{50}=3200$, and O172:NM strain a $\mathrm{CD}_{50}=200$.

Athough in this assay show positive controls frank cytotoxic effect in this case was not possible to distinguish between strains harboring either toxin, which shows that the separation method used was not effective enough.

\section{Subtypification}

The isolated strains were analyzed by RAPD, using 970-11 and M-13 primers. RAPD profiles were inspected visually and defined according to the presence or absence of polymorphic bands. The similarity among the RAPD profiles was estimated by the DICE similarity coefficient. A dendrogram is shown in Figure 4.

Two main clusters can be observed, one more complex containing five little groups. Regarding strains charac-

Table 3 - Sensitivity patterns of antimicrobial agents.

\begin{tabular}{|c|c|c|c|c|c|c|}
\hline \multirow[t]{2}{*}{ Antimicrobial agent } & \multicolumn{2}{|c|}{ Susceptible } & \multicolumn{2}{|c|}{ Intermediate } & \multicolumn{2}{|c|}{ Resistant } \\
\hline & Number of strains & $\%$ & Number of strains & $\%$ & Number of strains & $\%$ \\
\hline Amicacine & 11 & 92 & 1 & 8 & 0 & 0 \\
\hline Ampicillin & 6 & 50 & 5 & 42 & 1 & 8 \\
\hline Ciprofloxacin & 2 & 100 & 0 & 0 & 0 & 0 \\
\hline Colisitin & 1 & 8 & 6 & 50 & 5 & 42 \\
\hline Chloramphenicol & 11 & 92 & 0 & 0 & 1 & 8 \\
\hline Gentamicin & 11 & 92 & 0 & 0 & 1 & 8 \\
\hline Nalidixic acid & 10 & 83 & 0 & 0 & 2 & 17 \\
\hline Nitrofurantoin & 9 & 75 & 3 & 25 & 0 & 0 \\
\hline Streptomycin & 11 & 92 & 0 & 0 & 1 & 8 \\
\hline Tetracycline & 10 & 83 & 1 & 8 & 1 & 9 \\
\hline Trimethoprim-sulphamethoxazole & 12 & 100 & 0 & 0 & 0 & 0 \\
\hline
\end{tabular}




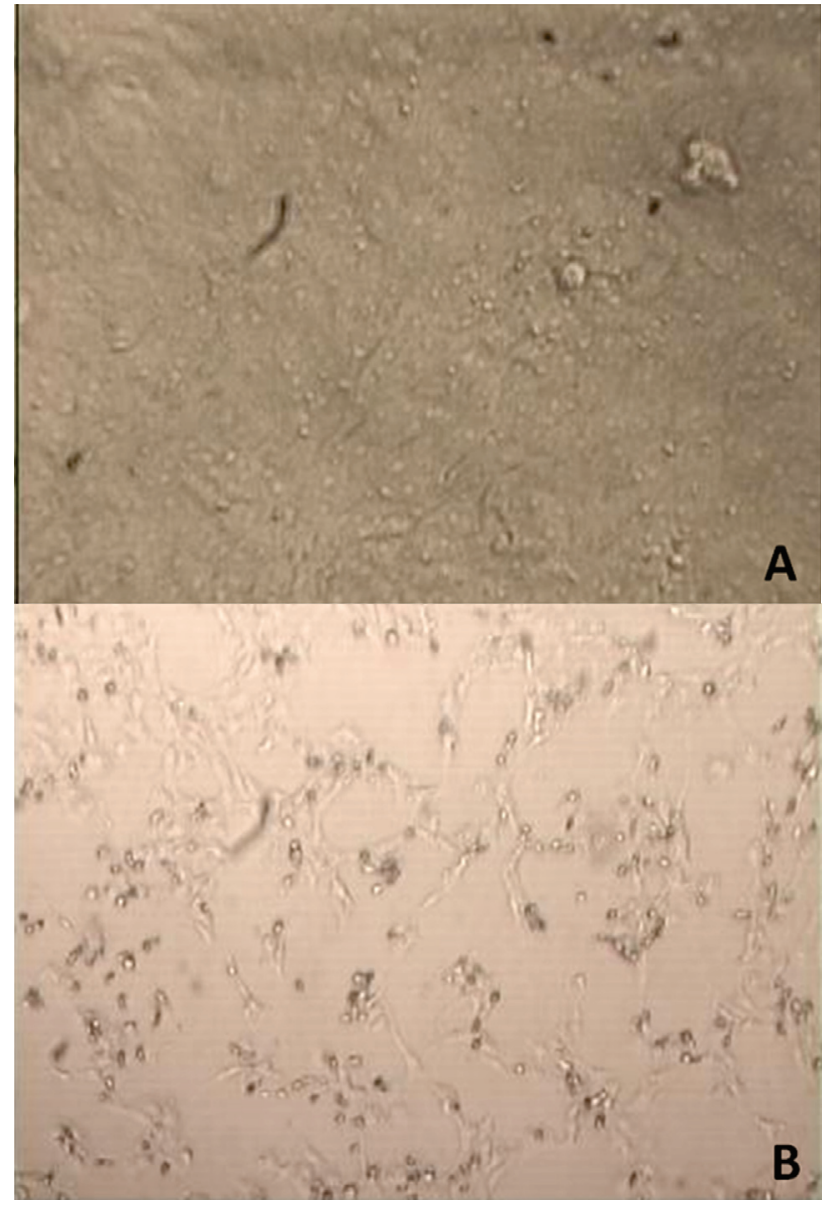

Figure 3 - Cytotoxic effect in Vero cells. (X 1,000) A. Uninfected monolayer. B. Infected monolayer with characteristic cytotoxic effect.

teristics such as virulence factors, antibiotic resistance, strain origin and serotype, each group was heterogeneous. It was not possible to establish any relationship between the members of any groups more than their genetic similarity.

\section{Discussion}

This is the first research project conducted in a slaughterhouse of Mendoza. The study was designed to investigate STEC in the intestinal content of healthy cattle and the transfer of fecal material to the carcass at slaughtering.

The positive strains were characterized in terms of their pathogenicity, serotype, antibiotype and molecular profile, in order to establish a database that may facilitate data crisscrossing in the event of the appearance of sporadic cases or outbreaks in humans.

The results of screening tests are in agreement with other studies conducted in our country (Meichtri et al., 2004; Padola et al., 2002; Rivero et al., 2004). STEC contamination was found on the cattle carcasses, though in smaller amounts than those found in intestines. After screening, when the colonies carrying the genes were reiso-

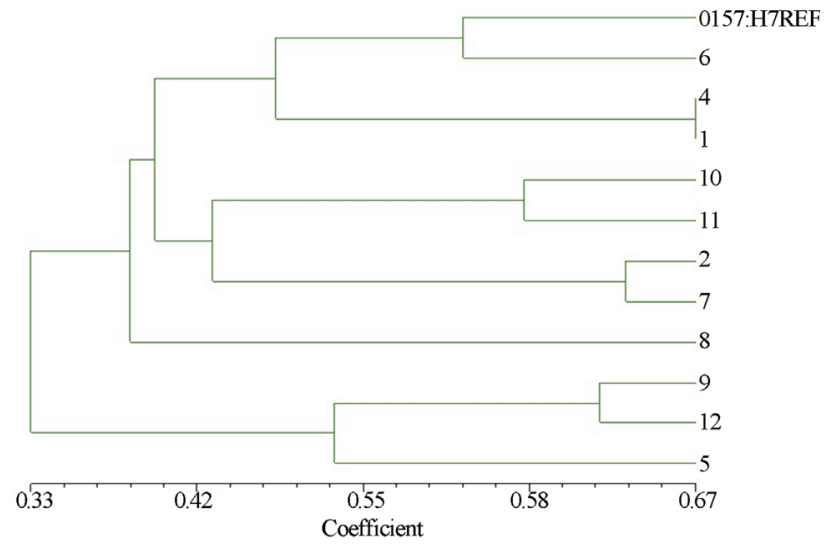

Figure 4 - The dendrogram illustrates the clonal structure and the genetic relationships of the 11 strains studied here. The strains are distributed through several groups related at different similarity levels.

lated, pure strains could be obtained in smaller amounts than by PCR. In fact, the recovered percentage fluctuated between $25 \%$ and $36 \%$. When PCR was repeated in pools of five colonies, samples remained positive, though isolation of colonies carrying the genes was difficult. This may be related to the high sensitivity of the PCR technique that can detect minimum DNA amounts per sample. Later, when trying to isolate the toxin-producing colony, the bacterial competition may have facilitated the disappearance of the colony. This dilemma may be resolved in future studies with the application of more selective methods or techniques such as inmunocapture, which we were unable to realize in our study. Regarding serotypification, a large amount of serogroups related to STEC were assayed, and some reported for other authors were found, such as O172:H(-), O178:H19, O2:H5, and O91:H21(Blanco et al., 2004; Hornitzky et al., 2005; Mellmann et al., 2009). Consistent with reports in other regions of our country, all strains were non-O157:H7. Despite the large panel of antisera used, we were unable to determine the serogroup of some isolates with the flagella types H16 (astA positive E.coli), H42 (Stx1 positive E.coli) and H46 (eae-positive, stx-deficient E. coli), suggesting that more STEC and EPEC serogroups remain to be identified. Some isolates did not react with any sera of the panel used for typing; therefore, they should be tested with other antisera that were not used on this study.

Those strains that showed toxin production potential by PCR were, in turn, studied in terms of their toxigenic capacity using a cytotoxicity assay on Vero cells. Among the strains with positive cytotoxicity reaction, the O91:H21, O172:H(-) and O178:H19 strains, all of them Stx2 positive, showed a strong cytotoxic effect. Finding serotype O91:H21 was relevant, as it is among those more closely related to human disease involving non-O157:H7 strains (Bielaszewska et al., 2009). Although this strain carries the virulence factor gene Stx2, it lacks the eae colonization factor that would make it a potential pathogen for humans. 
Further studies should be conducted to check if it carries any other adherence factor, such as saa.

The low level of resistance to antimicrobials may be associated with the fact that the most common cattle management system is free roaming on grassland, and food supplement containing antibiotics is not a common practice, possibly due to its high cost in this country. Strain characterization by the RAPD technique showed, in general, different profiles for each strain. The highest genetic relation found corresponded to $63 \%$. This percentage shows that the genetic component is not significant enough to suggest any kind of epidemiological relation (Tenover et al., 1995).

To conclude, the most significant aspects of this study are:

This is the first project carried out in an abattoir in the province of Mendoza, and the observed prevalence through screening was $23 \%$. This information is not significantly different from that observed in other regions.

The detailed detection and characterization of the aforementioned strains could eventually be used to draw comparisons in the event of an outbreak in humans.

These data prove that cattle carcasses are contaminated with STEC.

All the strains found were non-O157, in agreement with data from other regions of Argentina.

Our data indicate that cattle is a source of E.coli strains harboring serologically and genetically diverse pathogenic factors. From the information that was collected, we suggest keeping permanent surveillance in the cattle slaughterhouses, and planning strategies to prevent the spread of this foodborne pathogen.

\section{References}

Bielaszewska M, Stoewe F, Fruth A, Zhang W, Prager R, Brockmeyer J, Mellmann A, Karch H, Friedrich AW (2009) Shiga toxin, cytolethal distending toxin, and hemolysin repertoires in clinical Escherichia coli O91 isolates. J Clin Microbiol 47:2061-6.

Blanco M, Blanco JE, Mora A, Dahbi G, Alonso MP, Gonzalez EA, Bernardez MI, Blanco J (2004) Serotypes, virulence genes, and intimin types of Shiga toxin (verotoxin)-producing Escherichia coli isolates from cattle in Spain and identification of a new intimin variant gene (eae-xi). J Clin Microbiol 42:645-51.

Doyle MP, Schoeni JL (1984) Survival and growth characteristics of Escherichia coli associated with hemorrhagic colitis. Appl Environ Microbiol 48:855-6.

Gomez D, Miliwebsky E, Fernandez Pascua C, Baschkier A, Manfredi E, Zotta M, Nario F, Piquin A, Sanz M, Etcheverria A, Padola N, Parma A, Rivas M (2002) [Isolation and characterization of Shiga-toxin-producing Escherichia coli from frozen hamburgers and soft cheeses]. Rev Argent Microbiol 34:66-71.

Hornitzky MA, Mercieca K, Bettelheim KA, Djordjevic SP (2005) Bovine feces from animals with gastrointestinal infections are a source of serologically diverse atypical enteropathogenic Escherichia coli and Shiga toxin-producing E. coli strains that commonly possess intimin. Appl Environ Microbiol 71:3405-12.

Karmali MA, Gannon V, Sargeant JM (2010) Verocytotoxinproducing Escherichia coli (VTEC). Vet Microbiol 140:360-70.

MacFaddin JJ (2003) (ed) Pruebas Bioquímicas para la Identificación de Bacterias de Importancia Clínica. Editorial Médica Panamericana, Buenos Aires.

Marzocca MA, Marucci PL, Sica MG, Alvarez EE (2006) [Escherichia coli $\mathrm{O} 157: \mathrm{H} 7$ detection in fresh ground beef and hamburgers]. Rev Argent Microbiol 38:38-40.

McNally A, Roe AJ, Simpson S, Thomson-Carter FM, Hoey DE, Currie C, Chakraborty T, Smith DG, Gally DL (2005) Differences in levels of secreted locus of enterocyte effacement proteins between human disease-associated and bovine Escherichia coli O157. Infect Immun 73:2571.

Meichtri L, Miliwebsky E, Gioffre A, Chinen I, Baschkier A, Chillemi G, Guth BE, Masana MO, Cataldi A, Rodriguez HR, Rivas M (2004) Shiga toxin-producing Escherichia coli in healthy young beef steers from Argentina: prevalence and virulence properties. Int J Food Microbiol 96:189-98.

Mellmann A, Fruth A, Friedrich AW, Wieler LH, Harmsen D, Werber D, Middendorf B, Bielaszewska M, Karch H (2009) Phylogeny and disease association of Shiga toxin-producing Escherichia coli O91. Emerg Infect Dis 15:1474-7.

Mercado EC (2007) Haemolytic uremic syndrome: why Argentina?. Rev Argent Microbiol 39:191-2.

Miliwesbsky ED, N, Rivas M (2006) "Manual de Procedimientos Diagnósticos de Escherichia coli productor de Toxina Shiga O157 y no-O157 en alimentos por separación inmunomagnética y PCR", A.N.L.I.S. “Dr. Carlos Malbrán”.Servicio de Fisiopatogenia, Departamento de Bacteriología.

Ollero M, Junaidi O, Zaman MM, Tzameli I, Ferrando AA, Andersson C, Blanco PG, Bialecki E, Freedman SD (2004) Decreased expression of peroxisome proliferator activated receptor gamma in cftr-/- mice. J Cell Physiol 200:235-44.

Padola NL, Sanz ME, Lucchesi PM, Blanco JE, Blanco J, Blanco M, Etcheverria AI, Arroyo GH, Parma AE (2002) First isolation of the enterohaemorrhagic Escherichia coli O145:Hfrom cattle in feedlot in Argentina. BMC Microbiol 2:6.

Padola NL, Sanz ME, Blanco JE, Blanco M, Blanco J, Etcheverria AI, Arroyo GH, Usera MA, Parma AE (2004) Serotypes and virulence genes of bovine Shigatoxigenic Escherichia coli (STEC) isolated from a feedlot in Argentina. Vet Microbiol 100:3-9.

Pass MA, Odedra R, Batt RM (2000) Multiplex PCRs for identification of Escherichia coli virulence genes. J Clin Microbiol 38:2001-4.

Pichel MC, A Bilstein N (2006) IV Curso de Epidemiología Molecular en la Vigilancia de Infecciones Bacterianas. Servicio de Enterobacterias. A.N.L.I.S. "Dr. Cralos G: Malbrán”, Instituto Nacional de Enfermedades Infecciosas.

Pollard DR, Johnson WM, Lior H, Tyler SD, Rozee KR (1990) Rapid and specific detection of verotoxin genes in Escherichia coli by the polymerase chain reaction. J Clin Microbiol 28:540-5.

Prado V, Solari V, Alvarez IM, Arellano C, Vidal R, Carreno M, Mamani N, Fuentes D, O'Ryan M, Munoz V (2002) [Epidemiological situation of foodborne diseases in Santiago, Chile in 1999-2000]. Rev Med Chil 130:495-501. 
Rivas M (2009) Epidemiology of STEC/VTEC in South America. In: $7^{\circ}$ International Symposium on Shiga Toxin (Verocytotoxin) Producing Escherichia coli Infections (Ed), Asociacion Argentina de Microbiología, Buenos Aires.

Rivas M, Miliwebsky E, Chinen I, Roldan CD, Balbi L, Garcia B, Fiorilli G, Sosa-Estani S, Kincaid J, Rangel J, Griffin PM (2006) Characterization and epidemiologic subtyping of Shiga toxin-producing Escherichia coli strains isolated from hemolytic uremic syndrome and diarrhea cases in Argentina. Foodborne Pathog Dis 3:88-96.

Rivero MA, Padola NL, Etcheverria AI, Parma AE (2004) Enterohemorrhagic Escherichia coli and hemolytic-uremic syndrome in Argentina. Medicina (B Aires) 64:352-6.

Ruttler ME, Yanzon CS, Cuitino MJ, Renna NF, Pizarro MA, Ortiz AM (2006) Evaluation of a multiplex PCR method to detect enteroaggregative Escherichia coli. Biocell 30:301-8.

Ruttler ME, Renna NF, Balbi L, Garcia B, Guidone L, Fernandez R, Puig O, Ortiz A (2002) Characterization of enteroag- gregative Escherichia coli strains isolated from children with acute diarrhea, in Mendoza, Argentina. Rev Argent Microbiol 34:167-70.

Tenover FC, Arbeit RD, Goering RV, Mickelsen PA, Murray BE, Persing DH, Swaminathan B (1995) Interpreting chromosomal DNA restriction patterns produced by pulsed-field gel electrophoresis: criteria for bacterial strain typing. J Clin Microbiol 33:2233-9.

Veilleux S, Dubreuil JD (2006) Presence of Escherichia coli carrying the EAST1 toxin gene in farm animals. Vet Res 37:3-13.

Xia X, Meng J, McDermott PF, Ayers S, Blickenstaff K, Tran TT, Abbott J, Zheng J, Zhao S (2010) Presence and characterization of shiga toxin-producing Escherichia coli and other potentially diarrheagenic E. coli strains in retail meats. Appl Environ Microbiol 76:1709-17.

All the content of the journal, except where otherwise noted, is licensed under a Creative Commons License CC BY-NC. 